\title{
Preserved Capillary Density of Dorsal Finger Skin in Treated Hypertensive Patients with or without Type 2 Diabetes
}

\section{THESE}

préparée sous la direction du Professeur François Feihl (avec la co-direction du Professeur Bernard Waeber) et présentée à la Faculté de biologie et de médecine de l'Université de Lausanne pour l'obtention du grade de

\author{
DOCTEUR EN MEDECINE
}

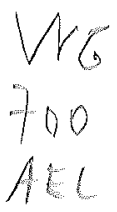

Par Jérôme AELLEN

Médecin diplômé de la Confédération Suisse

Originaire de Saanen (Berne) 


\section{Preserved Capillary Density of Dorsal Finger Skin in Treated Hypertensive Patients with or without Type 2 Diabetes}

\section{JEROME AELLEN, *,1 AMIN DABIRI, *,1 ABIGAEL HEIM, * LUCAS LIAUDET, ${ }^{\dagger}$ MICHEL BURNIER, ${ }^{\ddagger}$ JUAN RUIZ, ${ }^{\S}$ FRANÇOIS FEIHL,* AND BERNARD WAEBER*}

${ }^{*}$ Division de Physiopathologie Clinique; †Service de Médecine Intensive Adulte; $\ddagger$ Service de Néphrologie et Hypertension; $\$$ Service d'Endocrinoloige, Diabétologie et Métabolisme, Centre Hospitalier Universtaire Vaudois and Université de Lausanne, Lausanne, Switzerland Address for correspondence: Prof. François Feihl, PPA, BH10-701, CHUV, CH-1011 Lausanne, Switzerland. E-mail: francois.feihl@chuv.ch Previous presentation: Oral communication at the meeting of the European Society of Hypertension, June 20, 2011, Milano, Italy

${ }^{I}$ These authors have equally contributed to the study.

Received 1 September 2011; accepted 30 April 2012.

\section{ABSTRACT}

Objectives: Capillary rarefaction is a hallmark of untreated hypertension. Recent data indicate that rarefaction may be reversed by antihypertensive treatment in nondiabetic hypertensive patients. Despite the frequent association of diabetes with hypertension, nothing is known on the capillary density of treated diabetic patients with hypertension.

Methods: We enrolled 21 normotensive healthy, 25 hypertensive only, and 21 diabetic (type 2) hypertensive subjects. All hypertensive patients were treated with a blocker of the renin-angiotensin system, and a majority had a home blood pressure $\leq 135 / 85 \mathrm{mmHg}$. Capillary density was assessed with videomicroscopy on dorsal finger skin and with laser Doppler imaging on forearm skin (maximal vasodilation elicited by local heating).
Results: There was no difference between any of the study groups in either dorsal finger skin capillary density (controls $101 \pm 11$ capillaries $/ \mathrm{mm}^{2}$, nondiabetic hypertensive $99 \pm 16$, diabetic hypertensive $96 \pm 18, p>0.5$ ) or maximal blood flow in forearm skin (controls $666 \pm 114$ perfusion units, nondiabetic hypertensive $612 \pm 126$, diabetic hypertensive $620 \pm 103, p>0.5$ ).

Conclusions: Irrespective of the presence or not of type 2 diabetes, capillary density is normal in hypertensive patients with reasonable control of blood pressure achieved with a blocker of the renin-angiotensin system.

Key words: hypertension, capillaries, microcirculation, videomicroscopy, diabetes mellitus

Abbreviation used: $A C E$, angiotensin-converting enzyme; $A R B$ angiotensin receptor blocker; LDI, laser Doppler imaging; PU, perfusion units.

Please cite this paper as: Aellen J, Dabiri A, Heim A, Liaudet L, Burnier M, Ruiz J, Feihl F, Waeber B. Preserved capillary density of dorsal finger skin in treated hypertensive patients with or without type 2 diabetes. Microcirculation 19: 554-562, 2012.

\section{INTRODUCTION}

The structural rarefaction of microvascular networks (capillary rarefaction) in various organs and tissues is presently believed to be a hallmark of all forms of hypertension $[17,37]$. Capillary rarefaction has been demonstrated in a variety of hypertensive experimental models, in tissues as diverse as skeletal muscle $[8,10,21,35,44,48]$, myocardium $[32,33,38,45-47,58]$, intestine [23], and skin [20]. In humans, quantitative evaluation of capillary density is mainly possible in the superficial dermis, with videocapillaroscopy of nailfold or dorsal finger skin. To maximize the number of open and therefore visible vessels, counting is carried out with venous return occluded by inflation of a finger or wrist cuff. With this method, skin capillary density has been consistently found to be $10-20 \%$ lower in patients with untreated hypertension, in comparison with normotensive controls $[6,13,43,49]$. This defect might be an early feature of hypertensive disease, as it was reported in borderline hypertensives [5], and even in normotensive offsprings of hypertensive parents [4].

Uncertainty remains on whether capillary rarefaction is a secondary manifestation of hypertension (it certainly can be, as shown by its occurrence in experimental hypertension) or whether it also expresses a primary abnormality of the vascular system, which might be linked to the later development of hypertensive disease (as suggested by the aforementioned data in normotensive subjects). We are 
also far from completely understanding the processes involved in the hypertensive reduction of capillary density. These are nevertheless increasingly thought of in terms of an imbalance between vessel destruction (e.g., endothelial cell apoptosis caused by oxidant stress [31], the latter possibly related to the abnormal, activation of membranebound NADPH oxidase by angiotensin II) and regeneration through vasculogenesis and/or angiogenesis [17]. Consistent with this concept, cancer patients receiving antiangiogenic therapy simultaneously develop hypertension and capillary rarefaction $[41,55]$.

Whether a primary or secondary phenomenon, capillary rarefaction is increasingly believed to play a role in the pathogenesis of hypertensive end-organ damage, notably by promoting tissue ischemia $[17,24]$. It is thus important to know if it can be reversed by antihypertensive treatment. Many, although not all, experimental studies suggest a positive answer to this important question $[17,24]$. On the clinical side, two cross-sectional surveys have reported that treated hypertensive patients in whom control of blood pressure was satisfactory had a higher-indeed normal, or even supranormal - capillary density in dorsal finger skin, in comparison with untreated [13] or unsatisfactorily treated patients [12]. In addition, a low-salt diet was associated with an increased skin capillary density when compared with a high-salt diet in a cross-over trial carried out in mildly hypertensive subjects [22].

Of note, the aforementioned experimental and clinical studies have all been carried out in nondiabetic animals and patients. Diabetes and hypertension are frequently associated, aggressive lowering of blood pressure is particularly important in this condition [2], and diabetes has a specific impact on the microcirculation. One might therefore wonder whether diabetes can also induce rarefaction, and how it could possibly interact with hypertensive disease in that respect. There is almost no information relevant to this question in the literature.

In the present study, we have for the first time compared the skin capillary densities of hypertensive patients with or without type 2 diabetes. In both groups, a similar level of blood pressure control was achieved by a drug regimen that included at least one blocker of the renin-angiotensin system. Capillary density, measured by two different methods, was found identical in both groups of subjects, and did not differ from values obtained in healthy normotensive volunteers.

\section{MATERIAL AND METHODS}

\section{Subjects}

The study comprised three groups of subjects: hypertensive only, hypertensive and diabetic, and healthy normotensive volunteers (control). Enrolled subjects were caucasian, of either gender, aged $40-70$ years, and could be smokers or nonsmokers.
The patients, with or without diabetes, had been diagnosed and hypertensive according to current criteria by the European Society of Hypertension [16]. Hypertension could have been of any duration greater than two months, and must have been treated with a regimen including at least one blocker of the renin-angiotensin system for the last two months preceding enrollment into the study. This latter requirement was to improve the matching of the two hypertensive groups regarding drug treatment, as blockers of the renin-angiotensin system have become a compelling indication in hypertensive patients with diabetes. Hypertensive patients were classified as nondiabetic in the absence of any corresponding medical history, and provided that fasting blood glucose was $<5.6 \mathrm{mM}$ at inclusion time [1]. Hypertensive diabetic patients had type 2 diabetes of any duration, attested by medical history and ongoing treatment with either oral antidiabetic agents and/or insulin.

At enrollment time, normotensive healthy volunteers had unremarkable medical history and standard clinical examination, a blood pressure $<140 / 90 \mathrm{mmHg}$, a fasting blood glucose $<5.6 \mathrm{mM}[1]$, and a plasma creatinine $<110 \mu \mathrm{M}$. For the subjects to be retained in the final analysis, all these criteria had to be fulfilled a second time, on the second visit taking place approximately three months later (see below).

Pregnancy and active skin disease of any kind were exclusion criteria for all three groups. Hypertensive patients with or without diabetes were not included if on renal replacement therapy or with a plasma creatinine $>250 \mu \mathrm{M}$.

The enrollment of patients was through the relevant specialized outpatient clinics at our hospital. The recruitment of normotensive subjects was from hospital staff or through paper advertisement. The study was carried out in accordance with the principles outlined in the Declaration of Helsinki and was approved by the Ethical Committee competent for our institution. All participants gave written informed consent.

\section{Investigation of Capillary Density}

Capillaroscopy in dorsal finger skin. Skin capillaries were visualized with videomicroscopy in accordance with a methodology described by others [13]. The forearm was placed horizontally on an examination table, at heart level, with the subject in the sitting position. To maximize the number of visible capillary loops, venous congestion was created by inflating at $60 \mathrm{mmHg}$ a miniature pressure cuff placed around the base of the middle finger. The dorsal skin of its second phalanx was imaged, using an epi-illuminated fiber-optic microscope containing a $100 \mathrm{~W}$ halogen light source with a contact objective for a final magnification of 200 (PV100, Fort Imaging Systems, Dourdan, France). The epidermis was made translucent with immersion oil. The middle finger on the left and on the right side 
were both examined in this fashion. Microscopic video sequences were transferred for storage and further analysis to a $\mathrm{PC}$ via a video image converter. Static images were later extracted for the counting of capillary loops in 10 fields, 5 per side, each with an area of $1 \mathrm{~mm}^{2}$, using the Histolab software (Microvision, Paris, France), The final reported count was the mean of these 10 fields. This mean was used to calculate the descriptive statistics of the study, while statistical analysis was carried out on single counts (10 per subject) as explained below.

The counting of capillaries on the static images of the whole study was carried out by the same observer, who was blinded to their origin. Preliminary work established a between-observer coefficient of variation of approximately $5 \%$.

Maximal vasodilation in forearm skin. Local heating to a temperature of $42-44^{\circ} \mathrm{C}$ elicits maximal vasodilation in the dermis of forearm skin, as can be assessed from the measurement of dermal blood flow with laser Doppler flowmetry $[28,40]$. In healthy subjects, the maximal dermal blood flow recorded in these conditions has been positively correlated with capillary density measured as above $[26,42]$. In the present study, the maximal vasodilation induced by local heating in forearm skin was used as an additional index of capillary density.

Dermal blood flow was assessed using a laser Doppler imager (LDI, Moor Instruments, Axminster, UK). With this device, a laser beam $(633 \mathrm{~nm})$ scans the skin from a distance, allowing the mapping of blood flow over an area, which may range from a few $\mathrm{mm}^{2}$ to $10 \mathrm{~cm}^{2}$ or more, depending on instrument settings. The raw data may be postprocessed to obtain spatial averages on user-chosen subareas of interest.

Local heating was effected by means of custom made, annular, water-filled thermocontrolled chambers affixed to forearm skin with double-sided tape. An area of $0.8 \mathrm{~cm}^{2}$ of skin at the bottom of the chamber was accessible to the laser beam. The complete setup has been previously described by us in detail [11]. Two chambers were placed side-by-side, their temperature simultaneously raised from 34 to $43^{\circ} \mathrm{C}$ and kept at that value for 15 minutes, a time sufficient for the stabilization of dermal blood flow, which was recorded in parallel on both spots by scanning with the LDI device. The maneuver was then repeated on the contralateral arm. The final value for maximal dermal blood flow was the average of data recorded on the four spots and was retained as an index of capillary density. This index was used to calculate the descriptive statistics of the study, while statistical analysis was carried out on single vasodilatory responses (four per subject), as explained below.

\section{Protocol}

The study comprised two visits separated by approximately three months. Both visits took place in the same quiet $\beta$, temperature-controlled room, between 8 and 11 a.m. on working days, with the subjects reporting in the fasting state.

On Visit 1, criteria for eligibility and group allocation were checked. In all subjects, brachial blood pressure was measured (office BP) and peripheral venous blood was drawn for routine laboratory assessment, including blood glucose and plasma creatinine. Nothing more was done with normotensive volunteers, except scheduling the appointment for Visit 2. Hypertensive patients with or without diabetes were in addition given a validated oscillometric device (Omron) for the self-measurement of brachial blood pressure at home (home BP). They were instructed on its mode of operation and asked to carry out with it, in duplicate or preferably triplicate, two evaluations per day (morning and evening) of their blood pressure for the next three weeks. The appointment for Visit 2 was set up, and the patients were asked to also record their blood pressure twice a day during the three preceding weeks.

On Visit 2, home BP was retrieved from the oscillometric devices and stored on a computer. All measurements made on Visit 1 were repeated. Any healthy volunteer with an office $\mathrm{BP} \geq 140 / 90 \mathrm{mmHg}$ was excluded from further examination. All other subjects were invited to recline on a hospital bed. After 20 minutes of rest, maximal skin vasodilation was evaluated as described above. The subjects then were asked to sit at an examination table for the videomicroscopic determination of capillary density.

\section{Data Analysis}

For continuous variables, comparisons among the three groups were done with simple analysis of variance. For data regarding capillary density, four (thermal-induced vasodilation) or 10 values (capillaroscopy) were available for each subject. In these cases, we used a mixed-model ANOVA, including a single fixed factor with three levels (group), and patients as a random factor nested under group. When the $F$ value for the group effect was significant, pairwise comparisons were carried out with modified t-tests (Fisher's least significant differences). Chi-square tests were used for comparisons of categorical variables between groups. The alpha level of all tests was 0.05 . Data are summarized as means $\pm \mathrm{SD}$.

\section{RESULTS}

The study was completed by 67 subjects, 21 in the control group, 25 in the hypertensive only group, and 21 in the hypertensive + diabetic group. Their demographic and laboratory data, as recorded at the time of capillary density investigation (i.e., Visit 2), are shown in Table 1. The healthy, normotensive volunteers were on the average 
Table 1. Demographic and laboratory data

\begin{tabular}{|c|c|c|c|}
\hline & Control & $\begin{array}{l}\text { Hypertensive } \\
\text { only }\end{array}$ & $\begin{array}{l}\text { Hypertensive } \\
\text { and diabetic }\end{array}$ \\
\hline $\begin{array}{l}\text { Number of subjects } \\
\text { Demographic }\end{array}$ & 21 & 25 & 21 \\
\hline Gender (M/F) & $10 / 11$ & $17 / 8$ & $13 / 8$ \\
\hline Age (years) & $53 \pm 8$ & $61 \pm 8^{\star \star}$ & $61 \pm 7^{\star \star}$ \\
\hline Height $(\mathrm{cm})$ & $168 \pm 9$ & $172 \pm 10$ & $171 \pm 9$ \\
\hline Weight $(\mathrm{kg})$ & $66.0 \pm 11.8$ & $80.4 \pm 13.5^{* \star}$ & $92.1 \pm 15.4^{* *}+\dagger$ \\
\hline $\mathrm{BMI}\left(\mathrm{kg} / \mathrm{m}^{2}\right)$ & $23.3 \pm 3.1$ & $27.0 \pm 3.3^{\star \star}$ & $31.5 \pm 4.4^{* \star}+\dagger$ \\
\hline $\begin{array}{l}\text { Abdominal } \\
\text { circumference } \\
\text { (cm) }\end{array}$ & $86 \pm 11$ & $101 \pm 9^{\star *}$ & $110 \pm 13^{* *}+\dagger$ \\
\hline $\begin{array}{l}\text { Nonsmoker } \\
\text { Laboratory }\end{array}$ & 18 & $7^{* *}$ & $5^{* *}$ \\
\hline Glucose (mM) & $4.5 \pm 0.5$ & $5.5 \pm 0.9^{\star \star *}$ & $6.7 \pm 1.5^{* k+\varphi \dagger}$ \\
\hline Creatinine $(/ \mathrm{M})$ & $70 \pm 18$ & $84 \pm 13^{* *}$ & $78 \pm 20$ \\
\hline $\begin{array}{l}\text { Total cholesterol } \\
(\mathrm{mM})\end{array}$ & $5.3 \pm 0.8$ & $5.9 \pm 1.1$ & $4.8 \pm 1.2 \dagger \dagger$ \\
\hline $\mathrm{HDL}(\mathrm{mM})$ & $1.7 \pm 0.6$ & $1.4 \pm 0.4^{\star}$ & $1.2 \pm 0.4^{\star *}$ \\
\hline $\begin{array}{l}\text { Total } \\
\text { cholesterol/HDL }\end{array}$ & $3.4 \pm 1.1$ & $4.6 \pm 1.5^{* *}$ & $4.4 \pm 1.8^{\star}$ \\
\hline Triglycerides & $1.0 \pm 0.5$ & $1.9 \pm 1.1^{* *}$ & $2.1 \pm 1.1$ ** \\
\hline $\mathrm{LDL}(\mathrm{mM})$ & $3.1 \pm 0.9$ & $3.7 \pm 1.0^{\star}$ & $2.9 \pm 1.1 \uparrow \dagger$ \\
\hline $\mathrm{Hb}, \mathrm{Ac}(\%)$ & - & - & $6.7 \pm 0.8$ \\
\hline
\end{tabular}

Data recorded at the time of capillaroscopic examination (Visit 2), and presented as means \pm SD. Control subjects were nonhypertensive volunteers, ${ }^{*} p<0.05,{ }^{*} p<0.01$ vs Control $t p<0.05$, $\dagger$ $p<0.01$ hypertensive and diabetic vs hypertensive.

somewhat younger (by seven years), markedly leaner, and more frequent smokers than their hypertensive counterparts. The two hypertensive groups were well matched for age, sex ratio, and smoking habits, while obesity was more prevalent in the diabetics (BMI $\geq 30 \mathrm{~kg} / \mathrm{m}^{2}$ in $5 / 25$ hypertensive patients without and $15 / 21$ hypertensive patients with diabetes, $p<0.01$ ). Blood glucose was somewhat higher in the hypertensive only and markedly higher in the hypertensive and diabetic patients, in comparison with the healthy normotensive subjects. Concerning the lipid profile, the expected generalized trend toward abnormality separated the hypertensive only from the control group. Lipid abnormalities were less marked in hypertensive diabetics, who even had lower total cholesterol and identical LDL levels when compared with healthy normotensive subjects. Concomitantly, respectively 8 and 15 of these 21 patients had an $\mathrm{Hb}_{1} \mathrm{Ac}$ level $<6.5 \%$ and $7 \%$, attesting to generally excellent control of diabetes in this group, a quality, which according to a recent survey, seems usual in Switzerland and other western european countries [7]. Table 2 presents data related to the control of blood pressure. Not unexpectedly, office $\mathrm{BP}$ was higher in the two hypertensive group than in the control group, on both visits. In the
Table 2. Blood pressure at inclusion (Visit 1 ) and at the time of capillaroscopic examination (Visit 2)

\begin{tabular}{|c|c|c|c|}
\hline & Control & $\begin{array}{l}\text { Hypertensive } \\
\text { only }\end{array}$ & $\begin{array}{l}\text { Hypertensive } \\
\text { and diabetic }\end{array}$ \\
\hline \multicolumn{3}{|l|}{ Visit 1} & 21 \\
\hline \multicolumn{4}{|l|}{ Office BP $(\mathrm{mmHg})$} \\
\hline Systolic & $121 \pm 9$ & $139 \pm 16^{\star *}$ & $133 \pm 19^{\star *}$ \\
\hline Diastolic & $78 \pm 7$ & $86 \pm 8^{\star *}$ & $81 \pm 12$ \\
\hline \multicolumn{4}{|l|}{ Home BP $(\mathrm{mmHg})$. } \\
\hline Systolic & - & $133 \pm 9$ & $128 \pm 14$ \\
\hline Diastolic & - & $82 \pm 7$ & $77 \pm 8+$ \\
\hline \multicolumn{4}{|l|}{ Visit 2} \\
\hline \multicolumn{4}{|l|}{ Office BP (mmHg) } \\
\hline Systolic & $119 \pm 10$ & $136 \pm 15^{* *}$ & $131 \pm 13^{* *}$ \\
\hline Diastolic & $78 \pm 7$ & $85 \pm 8^{* *}$ & $81 \pm 8$ \\
\hline \multicolumn{4}{|l|}{ Home BP (mmHg) } \\
\hline Systolic & - & $136 \pm 3$ & $130 \pm 12$ \\
\hline Diastollc & - & $83 \pm 7$. & $78 \pm 7 \dagger$ \\
\hline
\end{tabular}

Visit 2 took place approximately three months after Visit 1. Control subjects were nonhypertensive volunteets. Home BP was recorded by hypertensive subjects, in the three weeks that followed Visit 1 and the three weeks the preceded Visit 2. Data are means \pm SD. ${ }^{\star} p<0.05,{ }^{* \star} p<0.01$ vs Control. $\dagger p<0.05$ hypertensive and diabetic vs hypertensive.

hypertensive only group, home $\mathrm{BP}$ was $\leq 135 / 85 \mathrm{mmHg}$ during the three weeks following Visit 1 and the three weeks preceding Visit 2 in respectively 13 and 11 of 25 patients. The corresponding numbers for the hypertensive and diabetic group were 15 and 14 of 21 patients. Thus, the overall quality of blood pressure control was somewhat better in the diabetics, but reasonable and relatively stable from Visit 1 to Visit 2 in both hypertensive groups.

The antihypertensive medications currently received on both visits are listed in the upper part of Table 3. Per design, all patients were on at least an inhibitor of the angiotensin-converting enzyme or an angiotensin II receptor antagonist on Visit 1, and remained so on Visit 2, with the rest of the medication changing very little between both visits. Antidiabetic medication was also quite stable from Visit 1 to Visit 2, with one-third of patients receiving insulin on both occasions (lower part of Table 3). Finally, one half of hypertensive subjects were on lipid lowering therapy, essentially with statins.

Whether directly measured with capillaroscopy on dorsal finger skin or indirectly evaluated from maximal dermal blood flow on the forearm, capillary density did not differ between the three study groups (Table 4). In post-hoc anal$y$ sis, none of these measurements of capillary density was correlated with either office BP, home BP, or HbAlc as recorded on Visit 2 (not shown). When using a threshold 
Table 3. Medications taken by hypertensive patients

\begin{tabular}{|c|c|c|c|c|}
\hline & \multicolumn{2}{|c|}{$\begin{array}{l}\text { Hypertensive } \\
\text { only }\end{array}$} & \multicolumn{2}{|c|}{$\begin{array}{l}\text { Hypertensive } \\
\text { and diabetic }\end{array}$} \\
\hline & Visit 1 & Visit 2 & Visit 1 & Visit 2 \\
\hline \multicolumn{5}{|c|}{ Renin-angiotensin system inhibitors } \\
\hline ACE inhibitors only & 8 & 7 & 10 & 10 \\
\hline ARB only & 17 & 18 & 10 & 10 \\
\hline Both & 0 & 0 & 1 & 1 \\
\hline \multicolumn{5}{|c|}{ Other antihypertensive agents } \\
\hline Diuretics & 19 & 19 & 17 & 16 \\
\hline$\beta$-Blockers & 7 & 7 & 6 & 5 \\
\hline $\begin{array}{l}\text { Calcium channels } \\
\text { blockers }\end{array}$ & 10 & 11 & 2 & 2 \\
\hline \multicolumn{5}{|l|}{ Antidiabetic agents } \\
\hline Oral only & - & - & 13 & 13 \\
\hline Insulin only & - & - & 5 & 5 \\
\hline Both & - & - & 3 & 3 \\
\hline \multicolumn{5}{|l|}{ Hypolipemic agents } \\
\hline Statins & 13 & 11 & 10 & 14 \\
\hline Fibrates & 0 & 0 & 1 & 1 \\
\hline
\end{tabular}

$A C E_{i}$ angiotensin-converting enzyme; $A R B$ angiotensin receptor blocker.

Table 4. Microvascular density data

\begin{tabular}{|c|c|c|c|}
\hline & Control & $\begin{array}{l}\text { Hypertensive } \\
\text { only }\end{array}$ & $\begin{array}{l}\text { Hypertensive } \\
\text { and diabetic }\end{array}$ \\
\hline Number of subjects & 21 & 25 & 21 \\
\hline $\begin{array}{l}\text { Capillary density (dorsa } \\
\text { capillary loops } / \mathrm{mm}^{2}\end{array}$ & $\begin{array}{l}\text { finger skin) } \\
101 \pm 11\end{array}$ & $99 \pm 16$ & $96 \pm 18$ \\
\hline \multicolumn{4}{|c|}{ Skin blood flow (forearm skin) } \\
\hline Baseline (PU) & $78 \pm 35$ & $84 \pm 47$ & $73 \pm 22$ \\
\hline Maximal (PU) & $666 \pm 114$ & $612 \pm 126$ & $620 \pm 103$ \\
\hline $\begin{array}{l}\text { Increase from } \\
\text { baseline to } \\
\max (P U)\end{array}$ & $588 \pm 119$ & $528 \pm 127$ & $546 \pm 101$ \\
\hline
\end{tabular}

Capillary density was directly measured with videomicroscopy on dorsal finger skin. On forearm skin, microvascular density was indirectly estimated from the maximal response of dermal blood flow to 15 minutes of local heating, from 34 (baseline) to $43^{\circ} \mathrm{C}$ (maximal). Skin blood flow, here expressed in perfusion units (PU), was recorded with laser Doppler imaging, on the volar face of forearms, in baseline conditions, and then after 15 minutes of local heating to a temperature of $43^{\circ} \mathrm{C}$. Control subjects were nonhypertensive volunteers. Data were obtained on Visit 2, and are presented as means \pm SD. There were not statistically significant between group differences.

HbAlc of $6.5 \%$ to divide the diabetic patients into two subgroups, the mean and $\mathrm{SD}$ of capillary density were respectively $102 \pm 19 \mathrm{cap} / \mathrm{mm}^{2} \quad(\mathrm{HbAlc} \leq 6.5 \%, n=12)$ and $89 \pm 15 \mathrm{cap} / \mathrm{mm}^{2}(\mathrm{HbAlc}>6.5 \%, n=9)$, a difference that was not statistically significant $(p=0.09)$.

\section{DISCUSSION}

In hypertensive patients who received a blocker of the renin-angiotensin system, we observed that capillary density was not reduced in comparison with a control group of healthy normotensive subjects, at least in dorsal finger and forearm skin. Our main new finding is that this statement holds independently of concomitant association of hypertension with type 2 diabetes.

As reviewed in the introduction, capillary rarefaction, whether assessed directly in dorsal finger skin $[4,6,13,49,50]$, or indirectly in forearm skin [42], has essentially been documented in untreated nondiabetic hypertensives $[6,13,49,50]$, or in normotensive nondiabetic subjects with risk factors for hypertension $[4,42]$. On the other hand, recent clinical studies have indicated that, at least in absence of diabetes, antihypertensive treatment can positively impact capillary rarefaction, or even completely normalize it, especially if the regimen includes an inhibitor of the renin-angiotensin system $[12,13,22]$. The lack of capillary rarefaction noted in the present study in the nondiabetic hypertensive patients is in accord with this recent literature. In particular, the degree of blood pressure control achieved in this group was, at least on average (Table 1), the same as that reported in the patient groups with normal or supranormal capillary density in the two aforementioned studies by Debabbi et al. $[12,13]$. Collectively, thesis studies, including the present one, support that capillary rarefaction, at least in the skin, is a hallmark of untreated hypertension, which may be reversed upon proper control of blood pressure, especially if carried out with blockers of the renin-angiotensin system.

Our study is the first one to specifically address the potential interaction of diabetes and hypertension in the modulation of capillary density. The information relevant to this question is surprisingly scarce in the literature, despite the frequent association of both diseases, and despite the major impact of diabetes on the microcirculation. Rarefaction was observed in skeletal muscle of obese Zucker rats [19,34], a model of type 2 diabetes, but these animals are also hypertensive [57], and nondiabetic controls of similar blood pressure were not available to these studies. In a murine normotensive model of type 1 diabetes induced by stretozotocin, several proangiogenic factors were downregulated and several antiangiogenic factors upregulated in skeletal muscle. These changes were associated with a reduced number of capillaries per muscle fiber, although the number of vessels per unit tissue cross-sectional area was not affected [30]. An abnormally low density of microvessels, selectively concerning those with a diameter $<30 \mu \mathrm{m}$, has been described in the conjunctiva of patients with type 2 diabetes [18]. The status 
of blood pressure was not documented in that study. In another clinical study [27], capillary density was measured with videomicroscopy in dorsal finger skin of 15 type 2 diabetics, 15 nondiabetic but glucose-intolerant subjects, and 15 controls with normal glucose tolerance. These three groups were well matched for age, gender, body mass index and blood pressure level (diastolic $<90 \mathrm{mmHg}$, systolic $<160 \mathrm{mmHg}$ ), and no difference in capillary density was found between either [27]. Finally, skin capillary density, assessed from maximal thermally induced vasodilation, did not differ between normoglycemic, normotensive human adults with and without genetic predisposition to type 2 diabetes [36].

In the present study, the diabetic and nondiabetic hypertensive patients were well matched for age (Table 1) and type of antihypertensive medication (Table 3 ). In addition, the quality of blood pressure control, assessed from 2 threeweek periods of home $\mathrm{BP}$ monitoring, was good in both groups (Table 2). Furthermore, management of diabetes was next to optimal, as attested by the high proportion of patients with satisfactory control of $\mathrm{HbA}_{1} \mathrm{c}$, and the relatively mild alterations noted in the lipid profile of this group (Table 1). Our results (Table 4) indicate that, in such conditions, irrespective of the presence or absence of type 2 diabetes, well-controlled hypertension is not associated with capillary rarefaction, at least in the skin microcirculation. If, as seems likely from the information reviewed above, hypertension-associated capillary rarefaction is reversible upon proper control of blood pressure, then our results mean that concomitant diabetes has no bearing on such reversibility.

The reasons for this state of affairs cannot be inferred from our data, and can only be speculated upon. We may note, for example, that the diabetic state has profound, and at times contradictory, influences on postnatal angiogenesis, which it may stimulate, due to local ischemia related to microvascular obstruction, as in the case of proliferative retinopathy [56], or hampered, among others by inducing dysfunction of crucial players such as endothelial progenitor cells $[15,54,56]$. Our data convey some suggestion that the quality of glucose control has an impact, as capillary density tended to be lowest in those diabetics with $\mathrm{HbAlc}$ above $6.5 \%$. This possibility would be consistent with the negative impact of hyperglycemia on the number and function of endothelial progenitor cells noted in several studies $[25,39]$. For its evaluation, a larger number of patients with more heterogenous metabolic control than in the present study would obviously be needed.

\section{Limitations}

The present study did not include groups of untreated hypertensive patients. With hypertensive diabetics, this would not have been ethically feasible, considering the paramount importance of blood pressure lowering in this con- dition [2]. Thus, the possibility remains that, regarding impact on capillary density, the natural history of combined diabetes and hypertension might differ from that of hypertension alone. In addition, conclusions might only be valid for patients with fairly well-controlled hypertension and diabetes, as was the case in the present study.

Capillary density in the skin tends to decrease with age [29], and the normotensive subjects were of younger age than the hypertensive patients (Table 1). This factor might have confounded comparisons between patients and controls, making it more difficult to detect the supranormal capillary density associated with good control of blood pressure, as observed in one of the studies cited above [12]. On the other hand, age was identical in diabetic and nondiabetic hypertensives, and therefore could nor influence comparisons made between these two groups.

In comparison with some of the previously mentioned reports, we have included a smaller number of subjects, which might leave our results open to the possibility of type II error. Calculations assuming 20 subjects per group (i.e., slightly less than the actual figures) and based on the within-subject variability of our capillaroscopic data indicate that the power to detect a $13 \%$ difference in the mean capillary density of any two groups was 0.8 at an alpha level of 0.05 . The differences reported by Debabbi et al. between the mean number of capillaries $/ \mathrm{mm}^{2}$ of age-matched normotensive subjects and hypertensive patients who were either untreated [13] or poorly controlled [12] were respectively $15 \%$ and $14 \%$. We would have been unlikely to miss effects of that size.

The respective contributions to our results of blood pressure lowering vs other, pressure-independent effects of the various drugs administered to the patients remain a matter of conjecture. Roughly half of the hypertensive subjects were on lipid-lowering therapy with statins (Table 3), compounds with known proangiogenic properties [14,51]. In an effort to reduce heterogeneity, the enrollment of patients was restricted to those receiving a blocker of the renin-angiotensin system, and there is strong experimental evidence for a proangiogenic effect of this drug class too $[52,53,59]$.

Finally, while in man the skin is the main available window into microcirculation, one may question whether it is representative of other vascular beds. This issue is not likely to be resolved in the near future. There is, however, some evidence for a correlation between abnormalities in the skin microcirculation and in other parts of the cardiovascular system. In patients with essential hypertension, a parallelism was described between the respective time courses of coronary flow reserve on one hand, and structural remodeling of small subcutaneous arteries on the other [9]. As another example, in a group of heart transplant recipients with greatly reduced exercise capacity, vasodilation induced by iontophoresis of acetylcholine in forerarm skin correlated with maximal $\mathrm{O}_{2}$ uptake as measured in a treadmill test [3]. 
In summary, the present study confirms the absence of capillary rarefaction in nondiabetic hypertensive patients in whom blood pressure is reasonably well controlled by drug treatment. It further indicates, for the first time, that this statement extends to hypertension combined with type 2 diabetes. This conclusion is at least valid if the drug regimen includes a blocker of the renin-angiotensin system, as was systematically the case here.

\section{PERSPECTIVE}

The present results add to the growing body of literature, indicating that hypertension-related capillary rarefaction may be reversible with proper treatment $[12,13,22]$. Future longitudinal studies should address the relationship of capillary density to ultimate cardiovascular outcome in both diabetic and nondiabetic hypertensive populations.

\section{ACKNOWLEDGMENTS}

The authors thank Guy Berset for excellent technical assistance, Pedro Marques-Vidal for statistical advice, and Steve Ayrton for English language editing.

\section{SOURCE OF FUNDING}

The study was funded by grant 32003B-116511 from the Swiss National Science Foundation.

\section{CONFLICT OF INTEREST}

None for any of the authors.

\section{REFERENCES}

1. American Diabetes Association. Diagnosis and classification of diabetes mellitus. Diabetes Care 28(Suppl 1): 537-\$42, 2005

2. American Diabetes Association. Treatment of hypertension in adults with diabetes. Diabetes Care 26(Supp/1): 580-S82, 2003.

3. Andreassen AK, Kvernebo $K$, Jorgensen $B$, Simonsen S, Kjekshus J, Gullestad L. Exercise capacity in heart transplant recipients: relation to impaired endothelium-dependent vasodilation of the peripheral microcirculation. Am Heart f 136: 320-328, 1998.

4. Antonios TFT, Rattray FM, Singer DRJ, Markandu ND, Mortimer PS, MacGregor GA. Rarefaction of skin capillaries in normotensive offspring of individuals with essential hypertension. Heart 89: 175178, 2003.

5. Antonios TFT, Singer DRJ, Markandu ND, Mortimer PS, MacGregor GA. Rarefaction of skin capillaries in borderline essential hypertension suggests an early structural abnormality. Hypertension 34: 655-658, 1999.

6. Antonios TFT, Singer DRJ, Markandu ND, Mortimer PS, MacGregor GA. Structural skin capillary rarefaction in essential hypertension. Hypertension 33: 9981001, 1999.

7. Banegas JR, Lopez-Garcia E, Dallongeville J, Guallar E, Halcox JP, Borghi C, MassoGonzalez EL, Jimenez FJ, Perk J, Steg PG, De Backer $G$, Rodriguez-Artalejo $F$. Achievement of treatment goals for primary prevention of cardiovascular disease in clinical practice across Europe: the EURIKA study. Eur Heart I 32: 21432152, 2011.
8. Boegehold MA, Johnson MD, Overbeck HW. Pressure-independent arteriolar rarefaction in hypertension. Am J Physiol 261: H83-H87, 1991.

9. Buus $N H$, Bottcher $M$, Jorgensen $C G$, Christensen $\mathrm{KL}$, Thygesen $\mathrm{K}$, Nielsen $T$, Mulvany MJ. Myocardial perfusion during long-term angiotensin-converting enzyme inhibition or beta-blockade in patients with essential hypertension. Hypertension 44: 465-470, 2004.

10. Chen II, Prewitt RL, Dowell RF. Microvascular rarefaction in spontaneously hypertensive rat cremaster muscle. Am J Physiol 241: H306-H310, 1981.

11. Ciplak M, Pasche A, Heim A, Haeberli C, Waeber B, Liaudet L, Feihl F, Engelberger $R$. The vasodilatory response of skin microcirculation to local heating is subject to desensitization. Microcirculation 16: 265-275, 2009.

12. Debbabi $H$, Bonnin P, Levy BI. Effects of blood pressure control with perindopril/indapamide on the microcirculation in hypertensive patients. Am J Hypertension 23: 1136-1143, 2010.

13. Debbabi H, Uzan L, Mourad JJ, Safar M, Levy BI, Tibirica E. Increased skin capillary density in treated essential hypertensive patients. Am J Hypertension 19: 477-483, 2006.

14. Dimmeler S, Aicher A, Vasa M, MildnerRihm $C$, Adler $K$, Tiemann M, Rutten $H$, Fichtlscherer $S$, Martin $H$, Zeiher AM. HMG-CoA reductase inhibitors (statins) increase endothelial progenitor cells via the PI 3-kinase/Akt pathway. I Clin Invest 108: 391-397, 2001.

15. Dimmeler S, Leri A. Aging and disease as modifiers of efficacy of cell therapy. Circ Res 102: 1319-1330, 2008.
16. European Society of Hypertension-European Society of Cardiology. 2003 European Society of Hypertension-European Society of Cardiology guidelines for the management of arterial hypertension. ) Hypertens 21: 1011-1053, 2003.

17. Feihl F, Liaudet $L$, Waeber B, Levy BI. Hypertension, a disease of the microcirculation? Hypertension 48: 1012-1017, 2006.

18. Fenton BM, Zweifach BW, Worthen DM Quantitative morphometry of conjunctival microcirculation in diabetes mellitus. Microvasc Res 18: 153-166, 1979.

19. Frisbee JC. Remodeling of the skeletal muscle microcirculation increases resistance to perfusion in obese Zucker rats. Am J Physiol 285: H104-H111, 2003.

20. Haack DW, Schaffer JJ, Simpson JG. Comparisons of cutaneous microvessels from spontaneously hypertensive, normotensive Wistar-Kyoto, and normal Wistar rats. Proc Soc Exp Biol Med 164: 453-458, 1980.

21. Hansen-Smith F, Greene AS, Cowley AW Jr, Lombard JH. Structural changes during microvascular rarefaction in chronic hypertension. Hypertension 15: 922-928, 1990.

22. He FJ, Marciniak M, Markandu ND, Antonios TF, MacGregor GA. Effect of modest salt reduction on skin capillary rarefaction in white, black, and Asian individuals with mild hypertension. Hypertension 56: 253-259, 2010.

23. Henrich $H$, Hertel $R$, Assmann R. Structural differences in the mesentery microcirculation between normotensive and spontaneously hypertensive rats. Pflugers Archiv 375: 153-159, 1978.

24. Humar R, Zimmerli L, Battegay E. Angiogenesis and hypertension: an update. J Human Hypertens 23: 773-782, 2009. 
25. Ingram DA, Lien $Z$, Mead LE, Estes $M$, Prater DN, Derr-Yellin E, DiMeglio LA, Haneline LS. In vitro hyperglycemia or a diabetic intrauterine environment reduces neonatal endothelial colony-forming cell numbers and function. Diabetes 57: 724731, 2008.

26. Irving RJ, Walker BR, Noon JP, Watt GCM, Webb DJ, Shore AC. Microvascular correlates of blood pressure, plasma glucose, and insulin resistance in health. Cardiovasc Res 53: 271-276, 2002.

27. Jaap AJ, Shore AC, Stockman AJ, Tooke JE. Skin capillary density in subjects with impaired glucose tolerance and patients with type 2 diabetes. Diabetic Med 13: 160-164, 1996.

28. Kellogg $\mathrm{DL}$ Jr, Pergola $\mathrm{PE}$, Piest $\mathrm{KL}$, Kosiba WA, Crandall CG, Grossmann $M$, Johnson IM. Cutaneous active vasodilation in humans is mediated by cholinergic nerve cotransmission. Circ Res 77: 1222-1228, 1995.

29. Kelly RI, Pearse R, Bull RH, Leveque $\mathrm{JL}$, de Rigal J, Mortimer PS. The effects of aging on the cutaneous microvasculature. $J \mathrm{Am}$ Acad Dermatol 33: 749-756, 1995.

30. Kivela $R$, Silvennoinen M, Touvra AM, Lehti TM, Kainulainen $H$, Vihko $V$. Effects of experimental type 1 diabetes and exercise training on angiogenic gene expression and capillarization in skeletal muscle. FASEB J 20: 1570-1572, 2006.

31. Kobayashi N, Delano FA, SchmidSchšnbein GW. Oxidative stress promotes endothelial cell apoptosis and loss of microvessels in the spontaneously hypertensive rats. Arterioscler Thromb Vasc Biol 25: 2114-2121, 2005.

32. Kobayashi N, Kobayashi K, Hara K, Higashi T, Yanaka $H$, Yagi $S$, Matsuoka $H$. Benidipine stimulates nitric oxide synthase and improves coronary circulation in hypertensive rats. Am J Hypertension 12: 483-491, 1999.

33. Larouche I, Schiffrin EL. Cardiac microvasculature in DOCA-salt hypertensive rats: effect of endothelin ET(A) receptor antagonism. Hypertension 34: 795-801, 1999.

34. Lash JM, Sherman WM, Hamlin RL. Capillary basement membrane thickness and capillary density in sedentary and trained obese Zucker rats. Diabetes 38: 854-860, 1989.

35. le Noble JL, Tangelder GJ, Slaaf DW, van Essen H, Reneman RS, Struyker-Boudier HA. A functional morphometric study of the cremaster muscle microcirculation in young spontaneously hypertensive rats. $J$ Hypertens 8: 741-748, 1990.

36. Lee BC, Shore AC, Humphreys JM, Lowe GD, Rumiey A, Clark PM, Hattersley AT, Tooke JE. Skin microvascular vasodilatory capacity in offspring of two parents with Type 2 diabetes. Diabetic Med 18: 541545, 2001.

37. Levy Bl, Ambrosio G, Pries AR, StruijkerBoudier HAJ. Microcirculation in hypertension - A new target for treatment? Circulation 104: 735-740, 2001.

38. Levy BI, Duriez M, Samuel JL. Coronary microvasculature alteration in hypertensive rats. Effect of treatment with a diuretic and an ACE inhibitor. Am / Hypertension 14: 7-13, 2001.

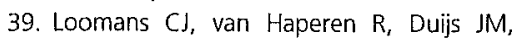
Verseyden $C$, de Crom $R$, Leenen PJ, Drexhage $H A$, de Boer $H C$, de Koning EJ, Rabelink TJ, Staal FJ, van Zonneveld AJ. Differentiation of bone marrow-derived endothelial progenitor cells is shifted into a proinflammatory phenotype by hyperglycemia. Mol Med 15: 152-159, 2009.

40. Minson CT, Berry LT, Joyner MJ. Nitric oxide and neurally mediated regulation of skin blood flow during local heating. $J$ Appl Physiol 91: 1619-1626, 2001.

41. Mourad JJ, des Guetz G, Debbabi H, Levy Bl. Blood pressure rise following angiogenesis inhibition by bevacizumab. A crucial role for microcirculation. Ann Oncol 19: 927-934, 2008.

42. Noon JP, Walker BR, Webb DJ, Shore AC, Holton DW, Edwards HV, Watt GC. Impaired microvascular dilatation and capillary rarefaction in young adults with a predisposition to high blood pressure. 1 Clin Invest 99: 1873-1879, 1997.

43. Prasad A, Dunnill GS, Mortimer PS, MacGregor GA. Capillary rarefaction in the forearm skin in essential hypertension. J Hypertens 13: 265-268, 1995.

44. Prewitt RL, Chen II, Dowell R. Development of microvascular rarefaction in the spontaneously hypertensive rat. $\mathrm{Am} /$ Physiol 243: H243-H251, 1982.

45. Rakusan K, Cicutti N, Kazda S, Turek Z. Effect of nifedipine on coronary capillary geometry in normotensive and hypertensive rats. Hypertension 24: 205-211, 1994.

46. Rakusan K, Cicutti N, Maurin A, Guez D, Schiavi $P$. The effect of treatment with low dose ACE inhibitor and/or diuretic on coronary microvasculature in stroke-prone spontaneously hypertensive rats. Microvasc Res 59: 243-254, 2000.

47. Sabri A, Samuel JL, Marotte F, Poitevin P, Rappaport L, Levy BI. Microvasculature in angiotensin II-dependent cardiac hypertrophy in the rat. Hypertension 32: 371-375 1998.

48. Scheidegger KJ, Wood JM, van Essen H, Struijker-Boudier HA. Effects of prolonged blockade of the renin angiotensin system on striated muscle microcirculation of spontaneously hypertensive rats. I Pharmacol Exp Ther 278: 1276-1281, 1996.

49. Serne EH, Gans ROB, ter Maaten JC, Tangelder GJ, Donker AJM, Stehouwer CDA. Impaired skin capillary recruitment in essential hypertension is caused by both functional and structural capillary rarefaction. Hypertension 38: 238-242, 2001.

50. Serne EH, Gans ROB, ter Maaten JC, ter Wee PM, Donker AM, Stehouwer CDA. Capillary recruitment is impaired in essential hypertension and relates to insulin's metabolic and vascular actions. Cardiovasc Res 49: 161-168, 2001.

51. Shao $H$, Tan $Y$, Eton $D$, Yang $Z$, Uberti MG, Li S, Schulick A, Yu H. Statin and stromal cell-derived factor-1 additively promote anglogenesis by enhancement of progenitor cells incorporation into new vessels. Stem Cells 26: 1376-1384, 2008.

52. Silvestre JS, Bergaya S, Tamarat R, Duriez $M$, Boulanger CM, Levy BI. Proangiogenic effect of angiotensin-converting enzyme inhibition is mediated by the bradykinin $\mathrm{B}(2)$ receptor pathway. Circ Res 89: 678683,2001

53. Silvestre JS, Tamarat $R$, Senbonmatsu $T$, Icchiki T, Ebrahimian T, Iglarz M, Besnard $S$, Duriez $M$, Inagami T, Levy Bl. Antiangiogenic effect of angiotensin II type 2 receptor in ischemia-induced angiogenesis in mice hindlimb. Circ Res 90: 10721079, 2002.

54. Sorrentino SA, Bahlmann FH, Besler C, Muller M, Schulz $S$, Kirchhoff $N$, Doerries $C$. Horvath $T$, Limbourg A, Limbourg $F$, Fliser D, Haller $H$, Drexler $H$, Landmesser $U$. Oxidant stress impairs in vivo reendothelialization capacity of endothelial progenitor cells from patients with type 2 diabetes mellitus: restoration by the peroxisome proliferator-activated receptorgamma agonist rosiglitazone. Circulation 116: 163-173, 2007.

55. Steeghs N, Gelderblom H, Roodt JO, Christensen $O$, Rajagopalan $P$, Hovens $M$, Putter $H$, Rabelink TJ, de Koning E. Hypertension and rarefaction during treatment with telatinib, a small molecule angiogenesis inhibitor. Clin Cancer Res 14: 34703476, 2008.

56. Tan K, Lessieur $E$, Cutler A, Nerone $P$, Vasanji A, Asosingh $K$, Erzurum S, AnandApte B. Impaired function of circulating CD34(+) CD45(-) cells in patients with proliferative diabetic retinopathy. Exp Eye Res 91: 229-237، 2010.

57. van Zwieten PA. Diabetes and hypertension: experimental models for pharmacological studies. Clin Exp Hypertension 21: 1-16, 1999. 
Bibliothèque Universitaire

de Médecine / BiUM

CHUV-BHO8 - Bugnon 46

$\mathrm{CH}-1011$ Lausanne

1. Aellen et al.

58. Xie Z, Gao M, Togashi H, Saito H, Koyama $T$. Improvement in the capillarity of the left ventricular wall of stroke-prone spontaneously hypertensive rats following angiotensin II receptor blockade. Clinical
\& Experimental Hypertension 21: 441452, 1999.

59. You D, Cochain C, Loinard C, Vilar J, Mees B, Duriez $M$, Levy BI, Silvestre JS. Hypertension impairs postnatal vasculo- genesis: role of antihypertensive agents. Hypertension 51: 1537-1544, 2008. 